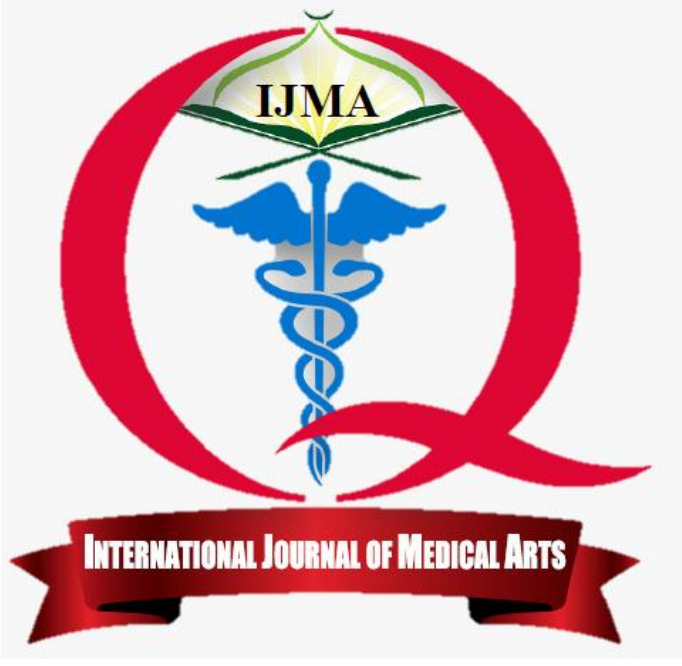

Available online at Journal Website

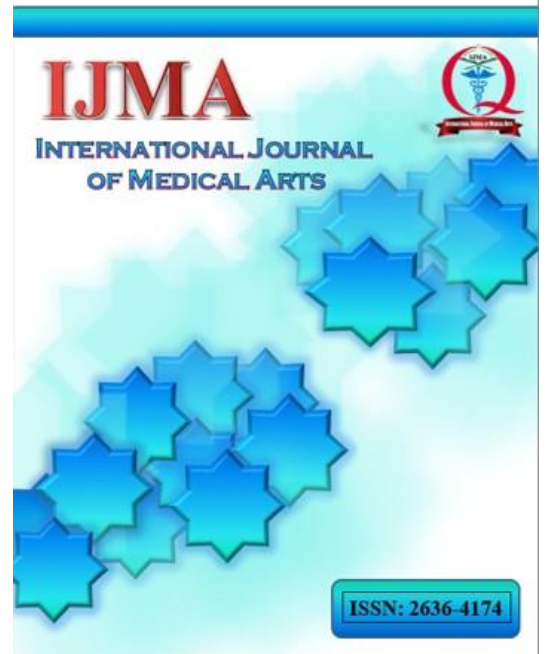

Original article

\title{
The effect of metabolic syndrome on outcome of acute exacerbation of chronic obstructive pulmonary disease (COPD)
}

\author{
Abo-bakr Helal Al-Asmara, Kamel Abd Elgafar Hassanº, Gamal Ahmed Mohamedc, Mohamed Elsayed Abd Elattif \\ Elsherbinyd
}

a. Chest Disease Department, Faculty of Medicine, Al-Azhar University (Cairo), Egypt.

b Chest Disease Department, Faculty of Medicine, Al-Azhar Faculty of Medicine (Damietta), Egypt.

c Clinical Pathology Department, Al-Azhar Faculty of Medicine (Damietta), Egypt

d Resident at Chest Disease Department; Al-Azhar Faculty of Medicine (Damietta), Egypt

\section{Corresponding author}

Mohamed Elsayed Abd Elattif Elsherbiny

Residnet at Chest Disease Department;

Al-Azhar Faculty of Medicine (Damietta), Egypt.

Email: mohamedhewidy1@gmail.com

Received at: May, 5, 2019

Accepted at: June 19, 2019

Available online at: June 28, 2019
Background: Metabolic syndrome is a multiorgan disease and it could aggravate other diseases. Its effect on chronic obstructive pulmonary disease needs to be addressed.

Aim of the work: to examine if metabolic syndrome increases the frequency, duration and severity of acute exacerbations of chronic obstructive pulmonary disease.

Methods: 60 patients who admitted with COPD exacerbation were included and were divided into two groups: Group 1 (COPD without metabolic syndrome). Group 2 (COPD with metabolic syndrome). All submitted to full history taking, clinical examination, laboratory and radiological examination.

Results: COPD severity was GOLD class II in $25.0 \%$, class III in $51.7 \%$ and class IV in 23.3\%; and disease severity was significantly higher in patients with metabolic syndrome. The frequency of COPD exacerbations showed significant increase in group 2 when compared to group 1 ( $2.17 \pm 0.65$ vs $1.43 \pm 0.57$ respectively). In addition, the duration of hospital stay increased significantly in group 2 when compared to group 1 (4.33 \pm 0.80 vs $3.37 \pm 0.61)$.

Conclusions: Metabolic syndrome could play a role in pathogenesis- or may be a consequence of- COPD. Thus, metabolic syndrome had a harmful effect on the outcome of COPD exacerbations

Keywords: Chronic obstructive pulmonary disease; Metabolic syndrome; Hypertension; Dyslipidemia; Exacerbation.

\section{DOI: $10.21608 / i j m a .2019 .37818$}




\section{Introduction}

Chronic obstructive pulmonary disease (COPD) is a common disease which characterized by limitation of airflow due to alveolar and/or airway disturbances triggered mainly by exposure to irritant particles or gases. The main characteristics of COPD is being preventable and treatable disease $^{[1]}$.

Patients with COPD had systemic inflammation beside the airway inflammation. However, the accurate relationship between systemic and airway inflammation is still not fully understood. Morbidity associated with COPD could be attributed to systemic inflammation ${ }^{[2-4]}$.

Epidemiological data revealed that, 384 million of people in 2010 had COPD, with a worldwide prevalence rate of $11.7 \%$, and there are three million deaths every year ${ }^{[5]}$.

In developing countries, smoking is increasing, while aging populations increase in developed countries. These two factors lead to expectation of increased prevalence of COPD in the next years. It is estimated that, by the year 3030, the annual deaths due to COPD patients expected to reach 4.5 million or more ${ }^{[6]}$.

The mechanism of systemic inflammation among COPD is believed to be related to oxidative stress and accounted for COPD-associated systemic diseases. Smoking, steroid use and abnormal bone marrow response could be potential causes contributing to systemic inflammation ${ }^{[7]}$. In addition, inflammatory markers such as $\mathrm{C}$-reactive protein, increased levels of interleukin- 6 and tumor necrosis factor alpha could contribute to the development of insulin resistance among COPD patients ${ }^{[8]}$. Insulin resistance usually accompany hypertension, dyslipidemia and obesity, which contribute metabolic syndrome ${ }^{[9]}$; a medical disorder which increase the risk of cardiovascular morbidity ${ }^{[10,11]}$.

Few numbers of previous studies found a positive link between metabolic syndrome and $\mathrm{COPD}^{[12,13]}$. However, controversy still exist.

\section{Aim of the work}

The aim of this study is to examine if metabolic syndrome increases the frequency, duration and severity of acute exacerbations of chronic obstructive pulmonary disease.

\section{Patients and methods}

It is prospective study that conducted in the department of chest disease, Al-Azhar University Hospital (New Damietta). A total of (60) patients who admitted with COPD exacerbation were included and were divided into two groups: Group 1 (COPD patients with exacerbation without metabolic syndrome). Group 2 (COPD patients with exacerbation with metabolic syndrome). Patients aged 40 to 60 years, with evidence of clinical, Lab or radiological evidence of COPD exacerbation were included. On the other side, patients with left sided heart failure, bronchial asthma or asthma COPD overlap, obstructive sleep apnea or interstitial lung disease were excluded from the study. All patients were subjected to history taking, physical "clinical" examination, chest X-ray of posterior-anterior and lateral views and spirometry by ZAN 100 spirometer (nSpire Health GmbH, Schlimpfhofer Straße 14, 97723 Oberthulba, Germany). In addition, high resolution computed tomography scanning of the chest was carried out for all patients. Laboratory investigations included arterial blood gases (ABGs), complete blood count (CBC), fasting and postprandial blood glucose levels, liver enzymes and serum creatinine. Inflammatory markers (e.g. CRP was determined using Pointe Scientific Kit, produced by Pointe Scientific Inc. Canton MI, USA). The test was done as described by Koenig et al. ${ }^{[14]}$. Also, erythrocyte sedimentation rate (ESR) was measured as described by Lee et al. ${ }^{[15]}$. Finally, lipid profile was measured as described by Artiss et al. ${ }^{[16]}$ and Seguchi et al. ${ }^{[17]}$.

\section{Statistical analysis of data:}

The obtained data of every patient were collected in a separate patient sheet then tabulated in a master table and fed to the computer on IBM SPSS version 20, statistical program for analysis of data. For quantitative data, mean and standard deviation were calculated. For qualitative data, frequency and percentage distribution were calculated. Test for significance of qualitative data was Chi- square. Test for significance of quantitative data was student $(\mathrm{t})$ test. $\mathrm{P}$ value of less than 0.05 was considered significant.

\section{Results}

In the present work, patient age ranged from 53 to 76 years; and there was no significant difference between groups one and two $(63.96 \pm 5.01$ vs $64.53 \pm 6.31$ respectively). The majority of patients were males (there was 37 males $(61.7 \%)$ and 23 females (38.3\%); and there was significant increase of females in group 2 when compared to group 1 (60.0\% vs $16.7 \%$ respectively). BMI of studied patients ranged from 22 to $44 \mathrm{~kg} / \mathrm{m} 2$; and there statistically significant decrease in BMI of group one when compared to group two $(25.36 \pm 1.80$ vs $37.30 \pm 2.47$ respectively). Smoking packs/year in 
the studied groups ranged from 0 to 50 and there was no significant difference between groups one and two $(24.13 \pm 15.40$ vs $24.37 \pm 15.99$ respectively). Systolic blood pressure ranged from 110 to 200 $\mathrm{mmHg}$ and there was significant decrease in SPB of group 1 when compared to group $2(125.00 \pm 8.20 \mathrm{vs}$ $174.67 \pm 15.70 \mathrm{mmHg}$ respectively). In addition, diastolic blood pressure ranged from 70 to 110 $\mathrm{mmHg}$ and there was significant decrease of group one when compared to group two $(84.33 \pm 7.28$ vs $97.00 \pm 5.96 \mathrm{mmHg}$ respectively). Respiratory rate ranged from 28 to 36 cycles/minute and there was no significant difference between groups one and two (30.17 \pm 2.29 vs $30.43 \pm 1.83$ respectively) (Table 1). There was no significant difference between groups one and two as regard to oxygen saturation, $\mathrm{pH}$, and arterial carbon dioxide tension, while there was significant decrease of oxygen tension in group two when compared to group1 $(53.40 \pm 2.47$ vs $67.07 \pm 4.86$ respectively). There was statistically significant decrease of FEV1 and FEV1/FVC in group one when compared to group two (Table 2).

WBCs ranged from 4.50 to $29.0 \times 10^{\wedge} 3 / \mathrm{ml}$, while hemoglobin concentration ranged from 13 to $19 \mathrm{~g} / \mathrm{dl}$ and platelets ranged from 178 to $393 \mathrm{x}$ $10^{\wedge} 3 / \mathrm{ml}$; and there was no significant difference between groups one and two. Creatinine ranged from 0.70 to $2.10 \mathrm{mg} / \mathrm{dl}$; and there was no significant difference between groups one and two ( $1.06 \pm 0.36$ vs $1.02 \pm 0.26$ respectively). Cholesterol ranged from 100 to $323 \mathrm{mg} / \mathrm{dl}$ with significant decrease in group one when compared to group 2 $(122.37 \pm 12.83$ vs $301.63 \pm 12.15$ respectively). In addition, there was significant decrease of group 1 when compared to group 2 regarding triglycerides $(97.13 \pm 13.78$ vs $275.07 \pm 15.71$ respectively). However, HDL was significantly increased of group 1 when compared to group 2 (77.40 \pm 7.36 vs $29.87 \pm 3.46 \mathrm{mg} / \mathrm{dl}$ respectively). Fasting blood sugar ranged from 75 to $188 \mathrm{mg} / \mathrm{dl}$ and there was significant decrease among group one when compared to group two $(80.07 \pm 2.33$ vs $141.53 \pm 23.39 \mathrm{mg} / \mathrm{dl}$ respectively). In addition, postprandial blood sugar ranged from 134 to $320 \mathrm{mg} / \mathrm{dl}$ and there was significant decrease among group one when compared to group two $(150.73 \pm 6.65$ vs $251.10 \pm 60.46 \mathrm{mg} / \mathrm{dl}$ respectively). There was no significant difference between groups one and two as regard to SGPT and SGOT. In addition, there was no significant difference between groups one and two as regard to ESR; while CRP was significantly increased in group two when compared to group one. Also, there was no significant difference between groups one and two as regard to serum sodium and potassium (Table 3 ).

ECG examination revealed that, $23.3 \%$ of studied population had sinus tachycardia; $11.7 \%$ had $\mathrm{p}$ pulmonale; $15.0 \%$ had right axis deviation and $50.0 \%$ had left axis deviation; and there was significant difference between groups one and two (where all patients in group 2 had left axis deviation, and no one in group one had no left axis deviation). Chest $x$ ray revealed that, 22 patients $(36.7 \%)$ had hyperinflated chest; and 17 patients $(28.3 \%)$ had chronic bronchitis, 21 patients $(35.0 \%)$ had emphysematous bullae and there was no significant difference between studied groups. HCRT examination revealed that, 23 patient $(38.3 \%)$ had centrilobular emphysema, 37 patients $(61.7 \%)$ had panacinar emphysema, with no significant difference between both groups.

In the present work, COPD severity was in the form of GOLD class II in 15 patients (25.0\%), class III in 31 patients $(51.7 \%)$ and class IV in 14 patients $(23.3 \%)$; and there was significant increase of grades III and IV in group 2 when compared to group $1(56.7 \%, 36.7 \%$ vs $46.7 \%$ and $10.0 \%$ respectively) (Table 4$)$.

In the present study, the frequency of COPD exacerbations in the last month ranged from once to thrice, and there was significant increase of frequencies in group 2 when compared to group 1 ( $2.17 \pm 0.65$ vs $1.43 \pm 0.57$ respectively). The duration of hospital stay (days) during the last exacerbation ranged from 3 to 6 days; and there was statistically significant increase in group 2 when compared to group 1 ( $4.33 \pm 0.80$ vs $3.37 \pm 0.61$ days respectively) (Table 5).

Table (1): Patient demographics, smoking blood pressure and respiratory rate among studied groups.

\begin{tabular}{|c|c|c|c|c|c|}
\hline & Group 1 & Group 2 & Test & $\mathrm{p}$ \\
\hline \multicolumn{2}{|l|}{ Age } & $63.96 \pm 5.01$ & $64.53 \pm 6.31$ & 0.38 & 0.70 \\
\hline \multirow{2}{*}{$\begin{array}{l}\text { Sex } \\
(\mathrm{n}, \%)\end{array}$} & Male & $25(83.3 \%)$ & $12(40.0 \%)$ & \multirow[t]{2}{*}{11.91} & \multirow[t]{2}{*}{$0.001 *$} \\
\hline & Female & $5(16.7 \%)$ & $18(60.0 \%)$ & & \\
\hline \multicolumn{2}{|l|}{ BMI } & $25.36 \pm 1.36$ & $37.30 \pm 2.47$ & 21.29 & $<0.001 *$ \\
\hline \multicolumn{2}{|c|}{ Smoking (packs/year) } & $24.13 \pm 15.40$ & $24.37 \pm 15.99$ & 0.05 & 0.95 \\
\hline \multirow[t]{2}{*}{ Blood pressure } & Systolic & $125.0 \pm 8.20$ & $174.67 \pm 15.70$ & 15.35 & $<0.001^{*}$ \\
\hline & Diastolic & $84.33 \pm 7.28$ & $97.0 \pm 5.96$ & 7.37 & $<0.001^{*}$ \\
\hline \multicolumn{2}{|l|}{ Respiratory rate } & $30.17 \pm 2.29$ & $30.43 \pm 1.83$ & 0.49 & 0.62 \\
\hline
\end{tabular}


Table (2): blood gases and respiratory functions among studied populations

\begin{tabular}{|l|c|c|c|c|}
\hline & Group 1 & Group 2 & Test & $\mathrm{p}$ \\
\hline $\mathrm{SaO} 2$ & $88.87 \pm 3.55$ & $89.80 \pm 2.81$ & 1.12 & 0.26 \\
\hline $\mathrm{pH}$ & $7.26 \pm 0.07$ & $7.27 \pm 0.08$ & 0.23 & 0.81 \\
\hline $\mathrm{PaO} 2$ & $67.07 \pm 4.86$ & $53.40 \pm 2.47$ & 13.72 & $<0.001^{*}$ \\
\hline $\mathrm{PCO} 2$ & $63.57 \pm 8.36$ & $62.12 \pm 12.55$ & 0.52 & 0.60 \\
\hline FEV1 & $31.23 \pm 2.97$ & $44.20 \pm 4.89$ & 12.42 & $<0.001^{*}$ \\
\hline FEV1/FVC & $57.47 \pm 9.19$ & $69.13 \pm 8.26$ & 5.17 & $<0.001^{*}$ \\
\hline
\end{tabular}

\begin{tabular}{|l|c|c|c|c|}
\hline \multicolumn{1}{|c|}{ Table (3): Lab investigations among studied populations } \\
\hline WBCs $\times 10^{\wedge} 3$ & Group 1 & Group 2 & Test & $\mathrm{p}$ \\
\hline Hemoglobin (g/dl) & $14.53 \pm 6.95$ & $12.78 \pm 7.28$ & 0.95 & 0.34 \\
\hline Platelets $\times 10^{\wedge} 3$ & $16.38 \pm 1.29$ & $16.67 \pm 1.12$ & 0.90 & 0.37 \\
\hline Creatinine & $252.33 \pm 63.30$ & $268.90 \pm 66.47$ & 0.98 & 0.32 \\
\hline Cholesterol & $1.06 \pm 0.36$ & $1.02 \pm 0.26$ & 0.57 & 0.56 \\
\hline Triglycerides & $122.37 \pm 12.83$ & $301.63 \pm 12.15$ & 55.65 & $<0.001^{*}$ \\
\hline High density lipoprotein & $97.13 \pm 13.78$ & $275.07 \pm 15.71$ & 45.83 & $<0.001^{*}$ \\
\hline Fasting blood sugar & $77.40 \pm 7.36$ & $29.87 \pm 3.46$ & 32.02 & $<0.001^{*}$ \\
\hline PP blood sugar & $80.07 \pm 2.33$ & $141.53 \pm 23.39$ & 14.31 & $<0.001^{*}$ \\
\hline SGPT & $150.73 \pm 6.65$ & $251.10 \pm 60.46$ & 9.03 & $<0.001^{*}$ \\
\hline SGOT & $35.17 \pm 8.17$ & $34.80 \pm 10.08$ & 0.15 & 0.87 \\
\hline ESR & $35.73 \pm 11.22$ & $35.17 \pm 12.30$ & 0.18 & 0.85 \\
\hline CRP & $25.67 \pm 17.31$ & $26.07 \pm 11.40$ & 0.10 & 0.91 \\
\hline Na & $17.63 \pm 6.06$ & $37.80 \pm 9.43$ & 0.93 & 0.35 \\
\hline K & $128.67 \pm 6.48$ & $125.80 \pm 4.96$ & 1.92 & 0.06 \\
\hline
\end{tabular}

Table (4): GOLD classification among studied groups.

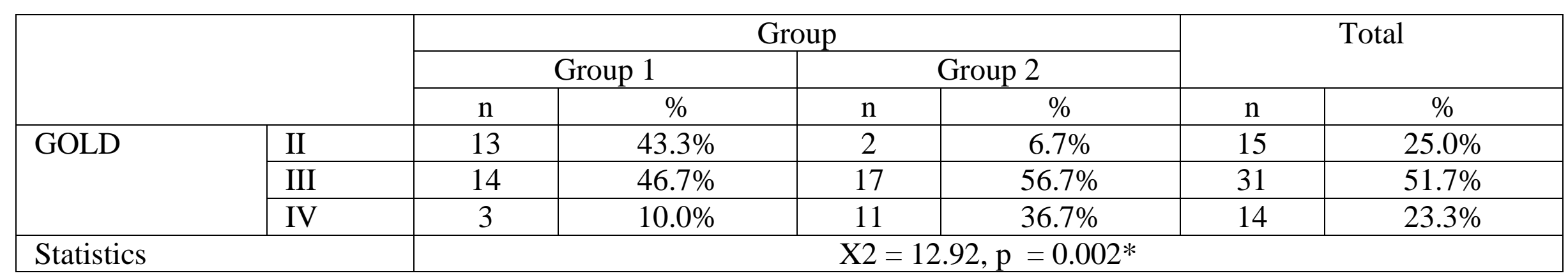

Table (5): Frequency of exacerbations during last year and duration of hospital stay (days) during last exacerbation among studied groups.

\begin{tabular}{|l|c|c|c|c|}
\hline & Group 1 & Group 2 & Test & $\mathrm{p}$ \\
\hline Exacerbation frequency & $1.43 \pm 0.57 ;$ & $2.17 \pm 0.65 ;$ & 4.66 & $<0.001^{*}$ \\
& $1-3$ & $1-3$ & & \\
\hline Duration of hospital stay & $3.37 \pm 0.61 ;$ & $4.33 \pm 0.80 ;$ & 5.23 & $<0.001^{*}$ \\
\hline
\end{tabular}

\section{Discussion}

Results of the present study revealed that, both groups were comparable as regard to patient's age. These results are agreed with Cebron Lipovec et al. $^{[17]}$ who reported mean age was $69 \pm 4$ and $68 \pm 5$ years in patients with metabolic and those with nonmetabolic syndromes respectively. In addition, results of the present work revealed that, COPD with metabolic syndrome was significantly prevalent in females, subjects with significantly higher body mass index and FEV1\%. These results were agreed with previous trials showed that, COPD subjects with metabolic syndrome were more frequently females, with higher BMI and FEV1\% compared to COPD patients without metabolic syndrome $e^{[18-20]}$. In addition, Cebron Lipovec et al. ${ }^{[17]}$ reported that, patients with metabolic syndrome in addition to COPD had higher body mass index, with high forced expiratory volume in one second predicted and were more prevalent in females. Furthermore, El-toney et al. ${ }^{[21]}$ reported that, BMI in subjects with COPD with metabolic syndrome was significantly higher than in patients with COPD without metabolic syndrome (30.6 vs. $27.8, \mathrm{P}=0.02$, respectively).

Smoking packs/year in the studied populations ranged from 0 to 50 and there was no significant difference between groups one and two $(24.13 \pm 15.40$ vs $24.37 \pm 15.99$ respectively). Cigarette smoking reported as the major risk factor for development of 
$\mathrm{COPD}^{[22]}$ and is one of the most significant risk factors for associated comorbidities ${ }^{[7]}$. Even, passive smoking play an important role in development of COPD and associated comorbidities ${ }^{[23]}$. Recurrent exposure to smoke and other irritants stimulates local airway inflammation with subsequent obstruction and decrease in FEV1\%, which is not fully reversible by bronchodilator therapy ${ }^{[24]}$. In addition, emphysema development is attributed to destruction of the terminal bronchiole walls caused by an proteases and anti-proteases imbalance in the lung by cigarette smoking ${ }^{[25-26]}$.

In the present study, according to GOLD classification there was significant increase of grades III and IV in-group 2 when compared to group 1 (56.7\%, 36.7\% vs $46.7 \%$ and $10.0 \%$ respectively; i.e., COPD severity increased with metabolic syndrome). These results coincides with previous studies, reporting that, COPD patients with metabolic syndrome had a more severe form of COPD reflected by more dyspnea, lower FEV1\% and need more medications (inhalation of glucocorticoids) ${ }^{[18]}$. The prevalence of metabolic syndrome and its associated comorbidities were linked to COPD severity and patient age ${ }^{[27]}$. However, another study revealed that, metabolic syndrome was reported in a large proportion of younger COPD patients and patients with less severe forms of COPD ${ }^{[28]}$. On the other hand, results of the present work disagree with Akpinar et al. ${ }^{[2]}$ who found that the distribution of the prevalence of metabolic syndrome between GOLD stages I-IV were as follows; $38.5 \%, 52.8 \%$, $30 \%$ and $33.3 \%$ respectively. Different inclusion criteria could explain such contradiction.

In the present study, the frequency of COPD exacerbations in the last year significantly increased in-group 2 when compared to group $1(2.17 \pm 0.65$ vs $1.43 \pm 0.57$ respectively). In addition, there was statistically significant increase in-group 2 when compared to group 1 according to the duration of hospital admission $(4.33 \pm 0.80$ vs $3.37 \pm 0.61$ days respectively). These results agree with the previous studies reported that, the existence of metabolic syndrome in subjects with COPD increases the incidence of exacerbations (2.4 vs. 0.7) and the duration of hospital admission (7.5 vs. 5.0 days) according to Kupeli et al. ${ }^{[30]}$, and 8 versus 5.5 days, according to Abdelghaffar et al. ${ }^{[31]}$.

In the present study, the duration of hospital stay (days) during the last exacerbation ranged from 3 to 6 days; and there was statistically significant increase in group 2 when compared to group $1(4.33 \pm 0.80$ vs $3.37 \pm 0.61$ days respectively). These results are $\mathrm{c}$ to those reported by Mannino et al. ${ }^{[32]}$ who reported that, patients with COPD who also have diabetes mellitus have increased duration of hospitalization than those without diabetes. In addition, Makarevich et al. ${ }^{[33]}$ reported that, COPD patients hospitalized with exacerbations, insulin resistance is associated with prolonged hospitalization, increased isolation of gram negative bacteria on sputum culture and elevated mean pulmonary arterial pressure.

In conclusion, metabolic syndrome parameters were significantly evident and could play a role in pathogenesis- or may be a consequence of- COPD. Whatever the situations, metabolic syndrome had a harmful effect on the outcome of COPD exacerbations.

\section{References}

1. Global Initiative for Chronic Obstructive Lung Disease guideline: Global strategy for the diagnosis, management and prevention of chronic obstructive pulmonary disease (updated 2019): Global Initiative for Chronic Obstructive Lung Disease; available at https://goldcopd.org/wpcontent/.../GOLD-2019-v1.7-FINAL-14 Nov 2018- WMS.pdf, Last accessed at April, 2019

2. Rabe KF, Wedzicha JA, Wouters EFM. Introduction. Rabe KF, Wedzicha JA, Wouters EFM (eds). COPD and Comorbidity. European Respiratory Society, Sheffield, 2013, ix-x

3. Agusti A, Soriano JB. COPD as a systemic disease. COPD.2008; 5 (2): 133-138. PMID: 18415812

4. Barnes PJ. Chronic obstructive pulmonary disease: Effects beyond the lungs. PLoS Med. 2010;7: e1000220. PMID:20305715.

5. Adeloye D, Chua S, Lee C, Basquill C, Papana A, Theodoratou E, et al. Global and regional estimates of COPD prevalence: Systematic review and meta-analysis. J Glob Health 2015; 5(2): 020415. PMID: 26755942.

6. Lopez AD, Shibuya K, Rao C, Mathers CD, Hansell AL, Held LS, Schmid V, Buist S. Chronic obstructive pulmonary disease: current burden and future projections. Eur Respir J 2006; 27(2): 397412. PMID: 16452599.

7. Fabbri LM, Rabe KF. From COPD to chronic systemic inflammatory syndrome? Lancet 2007; 370:797-9. PMID:17765529

8. Bolton CE, Evans M, Ionescu AA, Edwards SM, Morris RH, Dunseath G, et al. Insulin resistance and inflammation - A further systemic complication of COPD. COPD 2007;4:121-6. PMID:17530505 
9. Grimble RF. Inflammatory status and insulin resistance. Curr Opin Clin Nutr Metab Care 2002; 5:551-9. PMID:12172480

10. Alberti KG, Eckel RH, Grundy SM, Zimmet PZ, Cleeman JI, Donato KA, et al. Harmonizing the metabolic syndrome: a joint interim statement of the International Diabetes Federation Task Force on Epidemiology and Prevention; National Heart, Lung, and Blood Institute; American Heart Association; World Heart Federation; International Atherosclerosis Society; and International Association for the Study of Obesity. Circulation 2009; 120; 1640-1645. PMID: 19805654

11. Kaur J. A comprehensive review on metabolic syndrome. Cardiol Res Pract 2014; 2014; 943162. PMID:24711954

12. Marquis K, Maltais F, Duguay V, Bezeau AM, LeBlanc P, Jobin J, Poirier P. The metabolic syndrome in patients with chronic obstructive pulmonary disease. J Cardiopulm Rehabil 2005; 25:226-32. PMID:16056071

13. Watz H, Waschki B, Kirsten A, Muller KC, Kretschmar G, Meyer T, Holz O, Magnussen H. The metabolic syndrome in patients with chronic bronchitis and COPD: Frequency and associated consequences for systemic inflammation and physical inactivity. Chest 2009; 136:103946. PMID:19542257.

14. Koenig W, Sund M, Fischer HG, Löwel H, Döring A, Hutchinson WL, Pepys MB. C-Reactive Protein, a Sensitive Marker of Inflammation, Predicts Future Risk of Coronary Heart Disease in Initially Healthy Middle-Aged Men. Circulation 1999; 99: 237. PMID: 9892589.

15. Lee GR, Bithell TC, Foerster J, Athens JW, Lukens JN. Wintrobe's Clinical Hematology $9^{\text {th }}$ ed., Lea and Feblger Philadephia, 1993, pp 15-40.

16. Artiss JD, Zak B. Measurement of cholesterol concentration. In N Rifai, GR Warnick, MH Dominiczak (eds). Handbook of Lipoprotein Testing. AACC Press, Washington, 1997; pp 99114.

17. Cebron Lipovec N, Beijers RJ, van den Borst B, Doehner W, Lainscak M, Schols AM. The prevalence of metabolic syndrome in chronic obstructive pulmonary disease: A systematic review. COPD. 2016; 13:399-406. PMID: 26914392

17. Seguchi H, Uji Y, Okabe H, Irie T, Uekama K, Kayahara N, Miyauchi K. Direct measurement of high density lipoprotein cholesterol in serum with polyethylene glycol-modified enzymes and sulfated $\propto$-cyclodextrin. Clin Chem 1995; 41: 71723. PMID: 7729051

18. Diez-Manglano J, Barquero-Romero J, Almagro P, Cabrera FJ, Lopez Garcia F, Montero L, Soriano JB; Working Group on COPD; Spanish Society of Internal Medicine. COPD patients with and without metabolic syndrome: clinical and functional differences. Intern EmergMed 2014; 9(4):419-25. PMID: 23645508

19. Fumagalli G, Fabiani F, Forte $S$, Napolitano M, Marinelli $\mathbf{P}$, Palange $\mathbf{P}$, et al. INDACO project: a pilot study on incidence of comorbidities in COPD patients referred to pneumology units. Multidiscip Respir Med 2013; 8(1):28. PMID: 23551874.

20. Ozgen Alpaydin A, Konyar Arslan I, Serter S, Sakar Coskun A, Celik P, Taneli F, Yorgancioglu A. Metabolic syndrome and carotid intima-media thickness in chronic obstructive pulmonary disease. Multidiscip Respir Med 2013; 8(1):61. PMID: 24040911

21. El-toney AF, Mohamed BI, Abd-Elnaeem EA, Ismail AS. Metabolic syndrome; frequency and its relationship with variable parameters in chronic obstructive pulmonary disease. Egypt J Bronchol 2019; $13: 148-154$

22. Vogelmeier CF, Criner GJ, Martinez FJ, Anzueto A, Barnes PJ, Bourbeau J, et al. Global strategy for the diagnosis, management and prevention of chronic obstructive lung disease 2017 report: gold executive summary. Respirology 2017; 22: 575601. PMID: 28150362

23. Salvi SS, Barnes PJ. Chronic obstructive pulmonary disease in non-smokers. Lancet 2009; 374; 733 743. PMID: 19716966

24. Qureshi H, Sharafkhaneh A, Hanania NA. Chronic obstructive pulmonary disease exacerbations: latest evidence and clinical implications. Ther Adv Chronic Dis 2014; 5; 212227. PMID: 25177479

25. Abboud RT, Vimalanathan S. Pathogenesis of COPD. Part I. The role of protease-antiprotease imbalance in emphysema. Int J Tuberculosis Lung Dis 2008; 12; 361-367. PMID: 18371259

26. Kersul AL, Iglesias A, Rios A, Noguera A, Forteza A, Serra E, Agustí A, Cosio BG. Molecular mechanisms of inflammation during exacerbations of chronic obstructive pulmonary disease. Archivos de Bronconeumología 2011; 47; 176183.PMID:21454005

27. Hildrum B, Mykletun A, Hole T, Midthjell K, Dahl AA. Age-specific prevalence of the 
metabolic syndrome defined by the International Diabetes Federation and the National Cholesterol Education Program: the Norwegian HUNT 2 study. BMC Public Health 2007; 7; 220. PMID: 17727697

28. Minas M, Kostikas K, Papaioannou AI, Mystridou P, Karetsi E, Georgoulias P, et al. The association of metabolic syndrome with adipose tissue hormones and insulin resistance in patients with COPD without co-morbidities. COPD 2011;8, 414-420. PMID:22149401

29. Akpinar EE, Akpinar S, Ertek S, Sayin E, Gulhan M. Systemic inflammation and metabolic syndrome in stable COPD patients. Tuberk Toraks 2012; 60(3):230-237. PMID: 23030748

30. Kupeli E, Ulubay G, Ulasli SS, Sahin T, Erayman $\mathbf{Z}$, Gursoy A. Metabolic syndrome is associated with increased risk of acute exacerbation of COPD: a preliminary study. Endocrine 2010:38:76-82. PMID: 20960105

31. Abdelghaffar H, Tangour E, Fenniche S, Fekih L, Greb D, Akrout I, et al. Relation between metabolic syndrome and acute exacerbation of COPD. Eur Respir J 2012; 40(Suppl. 56):886s.

32. Mannino DM, Thorn D, Swensen A. Prevalence and outcomes of diabetes, hypertension and cardiovascular disease in COPD. Eur Respir J 2008; 32: 962-969. PMID:18579551

33. Makarevich AE, Valevich VE, Pochtavtsev AU. Evaluation of pulmonary hypertension in COPD patients with diabetes. Adv Med Sci. 2007; 52:265-72. PMID:18217431 